\title{
Article
}

\section{What is the impact of early rehabilitation following rotator cuff repairs on clinical and biomechanical outcomes? A randomised controlled trial}

Mazuquin, Bruno Fles, Monga, Punnet, Basu, Subhasis, Selfe, James and Richards, James

Available at http://clok.uclan.ac.uk/37863/

Mazuquin, Bruno Fles, Monga, Punnet, Basu, Subhasis, Selfe, James and Richards, James ORCID: 0000-0002-4004-3115 (2021) What is the impact of early rehabilitation following rotator cuff repairs on clinical and biomechanical outcomes? A randomised controlled trial. Physiotherapy Practice and Research, 42 (2). pp. 127-135. ISSN 2213-0683

It is advisable to refer to the publisher's version if you intend to cite from the work. http://dx.doi.org/10.3233/PPR-200489

For more information about UCLan's research in this area go to http://www.uclan.ac.uk/researchgroups/ and search for <name of research Group>.

For information about Research generally at UCLan please go to http://www.uclan.ac.uk/research/

All outputs in CLoK are protected by Intellectual Property Rights law, including Copyright law. Copyright, IPR and Moral Rights for the works on this site are retained by the individual authors and/or other copyright owners. Terms and conditions for use of this material are defined in the policies page. 
1 What is the impact of early rehabilitation following rotator cuff repairs on

2 clinical and biomechanical outcomes? A randomised controlled trial

\section{ABSTRACT}

4 Background: The number of rotator cuff repairs performed worldwide is increasing every year. However, there are still controversies regarding when rehabilitation after surgery should start.

7 Objectives: To assess and to compare clinical and biomechanical outcomes of patients who were randomised and allocated to early or conservative rehabilitation after rotator cuff repairs.

Methods: Twenty patients were randomised to two treatment groups. The biomechanical assessments were performed before surgery and at three and six months, consisting of 3D kinematics and muscle activity from 5 muscles (upper trapezius, anterior deltoid, middle deltoid, posterior deltoid and biceps brachii) from integrity.

Results: Overall, both groups had similar results for function and health-related quality of life. However, at six months patients in the early group had better range of motion (ROM) than those in the conservative group, especially for shoulder flexion (Early: median $=152.1^{\circ}$ vs Conservative: median $\left.=140.0^{\circ}\right)$. The number of re-tear symptoms at 12 months.

Conclusion: Early rehabilitation may improve ROM but it does not seem to be superior to a conservative management in improving function and quality of life. In 
addition, more re-tear events were observed in the early group. However, the results should be interpreted with caution due to the small sample size.

\section{INTRODUCTION}

Rotator cuff tear is a common disorder affecting approximately $30 \%$ of people older than 60 years (1) and it is responsible for almost 450,000 operations per year in the US (2). Rotator cuff tear can be debilitating and impair patients' quality of life and function; if initial non-operative treatments fail, surgical repair is often recommended (3). However, for optimal results, the postoperative rehabilitation must be adequately planned to help patients with their recover and return to daily activities (4).

Following a rotator cuff repair, a period of movement restriction is advised (5). Using a sling for six weeks is encouraged to protect the tendon and allow adequate softtissue healing and possibly avoid a re-tear (6). In contrast, delaying mobilisation may increase the risk of shoulder stiffness and potentially postpones improvements in function and return to work (7). Based on the available evidence, it is difficult to make an informed clinical decision on the most favourable postoperative time to start physiotherapy and reduce the use of sling. An overview of systematic reviews with updated meta-analyses demonstrated that, currently, there is almost the same number of systematic reviews compared with randomised controlled trials (RCTs) published on the topic, with reviews and primary studies showing conflicting conclusions (8).

In a clinical setting, it is common to use questionnaires to screen patients' impairments in activities of daily living (ADL) and goniometers to quantify range of motion (ROM). These tools have the advantage of being easy to use and are 
relatively inexpensive; however, their simplistic capacity for measurement may not objectively define how patients are affected and how they are recovering. For instance, the deltoid and upper trapezius muscles are activated for longer periods in patients having surgery for rotator cuff related problems but there is a lack of studies investigating if an early postoperative structured exercise program could be more effective than a conservative in readjusting the activity of the shoulder muscles $(9$, 10). Considering the uncertainties related to the application of early rehabilitation following rotator cuff repairs, and the lack of information on how different timing of starting physiotherapy affect muscle activation and quality of movement during ADLs after surgery; this study aimed to investigate the effectiveness of a therapist-led early rehabilitation regime compared with a conservative management on clinical and biomechanical outcomes.

\section{METHODS}

This study was an RCT which followed the CONSORT statement (11). Ethical approval was gained (16/NW/0143) and it was registered in the clinicaltrials.gov database (NCT02631486). The patients' recruitment and screening for eligibility were made on the same day that patients attended their scheduled appointments with the consultant regarding their shoulder symptoms and need for surgery. Potential patients were approached and informed about the study, this included what would happen if they agreed to take part and how their rehabilitation would progress. All participants signed an informed consent form after the study details were explained and any questions from the patient were addressed. 
The inclusion criteria consisted of 1) males and females aged between 40 and 70 years old (most common age range for rotator cuff tears) (1), 2) on the waiting list for a rotator cuff repair for a chronic tear (symptoms for $>3$ months), 3) with no other previous shoulder surgery on the same side, and 4) no other musculoskeletal impairment on the assessed limb or in the cervical and thoracic spine. Patients were excluded if 1) during the surgery a repair was deemed not needed or the tear was too extensive to allow early rehabilitation, 2) they had previous shoulder surgery and/or other musculoskeletal impairment on the assessed limb or in the cervical and thoracic spine, and 3) were unable to follow instructions.

\section{Intervention}

Rehabilitation consisted of two groups who received physiotherapy post-surgery with a planned frequency of once every two weeks, lasting for approximately 3-4 months. In the first stage (discharge to 4 weeks), patients in the Early group used the sling for comfort only, which could be discarded when the patient felt comfortable and confident in doing so; whereas the Conservative group was asked to remain in the sling until the $6^{\text {th }}$ week and remove it only to perform the prescribed exercises. The full protocols are available in the Supplementary file A. Treatment compliance and adherence were checked at the follow-up assessment sessions and were based on patients self-report on sling usage and attendance to physiotherapy.

\section{Randomization and allocation concealment}

A sequence of random numbers (www.randomization.com) was generated by an independent research team member (JR) who was also responsible for the allocation 
concealment. The opaque sealed envelopes were opened after surgery by one of the treating physiotherapists who was not involved with the study design or data analysis.

\section{Procedures}

Four assessment sessions were undertaken in the outpatient setting at baseline (before surgery), three, six and 12 months follow-up. The first three assessment sessions consisted of completing the Oxford Shoulder Score (OSS) for function, the EQ-5D-5L for health-related quality of life and a biomechanical assessment. The OSS is a 12 item questionnaire about pain and function commonly used in randomised controlled trials. It is valid, reliable and showed good responsiveness $(12,13)$. The EQ-5D is a generic questionnaire about quality of life which has been extensively used and researched and validated $(14,15)$. The assessments were led by an assessor (BM) who was blinded to patients' allocation until the final data analysis. The last assessment session at 12 months consisted of an ultrasound scan only. The scans were performed by a single Fellowship-trained Musculoskeletal Radiologist (SB), blinded to patient's group allocation, using a GE Logiq S8 ultrasound scanner (General Electric Healthcare; Chicago, United States of America).

\section{Biomechanical assessment}

The biomechanical assessment used two different systems that were synchronized; the Xsens MVN system (Xsens Tech®, Enschede, Netherlands) motion capture system which recorded upper body kinematics at $120 \mathrm{~Hz}$, and the Trigno (Delsys ${ }^{\circledR}$, Boston, USA) wireless EMG system which recorded muscle activity at $2000 \mathrm{~Hz}$. 
124 Every participant performed six shoulder movements and repeated each of them five times at a comfortable self-selected speed. The decision about using the tasks described in Table 1 was based on what is generally used during routine clinical assessments and common tasks used in everyday life that were assessed in similar studies (16-18). After determining the ROM (humerus in relation to the thorax) in degrees for each repetition, an average was calculated. For the EMG analysis, the muscles chosen were the anterior $(A D)$, middle $(M D)$ and posterior $(P D)$ deltoids, upper trapezius (UT) and biceps brachii (BC). These muscles are easy to access and are sensitive to changes to the rotator cuff muscles activation (19). The integral was calculated and expressed as a percentage of the peak value (20). All sensors were placed on each participant by the same assessor at every assessment session.

\section{Sample size calculation}

The primary outcome was shoulder ROM during flexion at 6 months. Based on a similar study (4), 14 patients would be needed in each group to detect a minimal clinically important difference (MCID) of $25^{\circ}$ of flexion ROM, with a standard deviation of $23.6^{\circ}$ at the $5 \%$ significance level, with $80 \%$ power. Adding $20 \%$ for eventual follow-up loss, the final total sample needed was 34 participants.

\section{Statistical Analysis}

Considering the number of patients recruited in each group and the number of patients that were reassessed at the follow-up points, descriptive statistics were preferred (21). We followed the intention-to-treat principle to report all outcomes. 
Ninety-nine patients were assessed for eligibility between May 2016 and January 2017; 57 were excluded as they did not agree to take part in the study. From the remaining 42, a further 22 were excluded: 17 did not need a rotator cuff repair and 5 had a massive tear, which were considered inappropriate for the early mobilisation protocol. Therefore, 20 patients were randomised, 10 per group (Figure 1).

\section{Figure 1}

157

158

\section{Table 2}

Table 3

\section{Physiotherapy compliance}

Seventy percent of patients in the Early group used the sling for less than 4 weeks and $88 \%$ of patients in the Conservative group used for at least 6 weeks (Table 4). Patients in the Early group reported a usage of $8.7(S D=10.6)$ hours per day $(\mathrm{h} / \mathrm{d})$ in comparison to $22.1 \mathrm{~h} / \mathrm{d}(\mathrm{SD}=3.5)$ in the Conservative group. The Early group had an average of $6.5(\mathrm{SD}=2.9)$ sessions with a physiotherapist and the Conservative group had an average of $8.7(\mathrm{SD}=4.3)$. 


\section{Clinical scores}

A large improvement from baseline was observed for both groups on both follow-ups for the OSS. Both groups had better scores for the EQ-5D-5L compared to baseline with equivalent values at 6 months (Table 5).

\section{Biomechanics}

180

\section{Combing}

At three months, the Conservative group showed slightly better ROM and higher muscle activity for the PD. At six months, the Early group had better ROM $\left(6.7^{\circ}\right.$ between groups difference) and similar muscle activity apart from the BC, which showed $18 \%$ higher activity in the Conservative group (Supplementary file B).

\section{Abduction}

Similar to the results of the Combing task, the Conservative group had better ROM at three months $\left(7.6^{\circ}\right.$ between groups difference $)$ and the Early group at six months, ( $14^{\circ}$ between groups difference). At three months, the Conservative group showed higher muscle activity for all muscles. At six months, the Early group showed higher activity of the $A D, M D$ and $B C$, with between groups differences of $15 \%, 9.6 \%$ and $25.8 \%$, respectively.

\section{Carrying}

For the Carrying task, the Conservative group showed higher ROM and EMG activity at three and six months, although the between groups differences for ROM were small; $0.2^{\circ}$ and $1.9^{\circ}$, respectively. The largest difference between groups for muscle activity was $18.8 \%$ for the MD at six months in favour of the Conservative group. 
The Early group had better ROM and muscle activity for the PD at three months $\left(4.9^{\circ}\right.$ and $11.7 \%$ between groups difference) and the Conservative at six months $\left(2^{\circ}\right.$ and $9.3 \%$ between groups difference).

Flexion

202

Comparing the follow-up values with baseline, the Early group improved $25^{\circ}$ at three months and over $45^{\circ}$ at six months. In contrast, the Conservative group had a reduction of approximately $6^{\circ}$ at three months and an improvement of $9^{\circ}$ at six months. The main between groups differences for muscle activity was for the MD (13.9\% in favour of the Conservative group) at three months and for the AD $(20.1 \%$ in favour of the Early group) and the PD (13.4\% in favour of the Conservative group) at six months.

\section{Lifting}

210 Comparing follow-up values with baseline, the Early group improved $40.7^{\circ}$ at three months and $68.9^{\circ}$ at six months, while the Conservative group got worse at three months by $9.5^{\circ}$ and improved by $9.6^{\circ}$ at six months. The main between groups differences for muscle activity was observed for MD (19.8\%) in favour of the Conservative group, and PD (12.1\%) in favour of the Early group at 3 months. At six months, the Early group showed greater activity for AD, MD and BC (28.4\%, $14.2 \%$ and $20.4 \%$, respectively).

\section{Repair Integrity}

Sixteen patients (Early $n=9$; Conservative $n=7$ ) had an ultrasound scan and six retears were found (Early $n=5$, Conservative $n=1$ ). Based on patients self-report, only 2 
patients, both from the Early group, reported any symptoms; all the others confirmed that they were satisfied and had no pain or difficulties with activities involving the shoulder.

\section{Table 5}

\section{DISCUSSION}

The study aimed to assess and to compare outcomes of patients who had a rotator cuff repair and were randomised to either early or conservative rehabilitation. We found that the majority of patients reported adhering to the use of the sling as per instructions, which corroborates with the study of Mazzocca, Arciero (22). In their study, the authors reported that the majority of patients in the trial comparing early with conservative rehabilitation following rotator cuff repairs also used the sling as requested. Although the information on sling usage from our study is important, it relies on patients' self-reported information, which may be prone to inaccuracies.

Overall, both groups improved self-reported function at both follow-ups with similar results at six months. However, it could be observed that the Early group continued to improve over time, while the Conservative group did not improve further at six months. Both groups improved above the OSS MCID of six points from baseline to six months $(23,24)$. Previous studies that have evaluated the effectiveness of rotator cuff repairs only have shown that the surgery is effective in improving function and quality of life of patients (25-27). Other RCTs on the topic have used different questionnaires, which limit direct comparisons. However, based on the MCID of each scale some estimations are possible. For example, the MCID for the ConstantMurley Score (0-100), is 11 and for the Simple Shoulder Test (0-12) is 2.2 points (23, 24). Using this approach, it is possible to observe the same trend on the RCTs 
reported by Kim, Chung (28) and Koh, Lim (29). These authors did not find statistically significant differences between groups at follow-ups, but both groups in both studies improved more than the MCID after 6 months.

Trying to compare the biomechanics results of the ADLs from this RCT to other studies is challenging due to the lack of similar design and hypotheses tested. Most studies with a similar method of assessment compared differences between healthy groups with patients who had the injury but were still untreated or compared patients after surgery versus healthy groups. For example, Vidt, Santago (30) assessed 7 functional activities comparing patients with rotator cuff tears to a healthy control group, which included two similar tasks (combing and upward reach) to those used in our study. Their results showed that for upward reaching, which was similar to the Flexion and Lifting tasks, patients with rotator cuff tears had approximately a $60^{\circ}$ range of motion in the sagittal plane. Another study, from Fritz, Inawat (31), 
$12.1^{\circ}$ for Flexion and $13.8^{\circ}$ for Lifting were observed. The MCID for shoulder flexion reported by Muir, Corea (32) is $14^{\circ}$ when measured with a goniometer. Considering that the glenohumeral relative angle was defined as the humerus in relation to the thorax, it could be possible that the difference between groups for ROM are clinically important; however, such analysis is beyond the scope of our study and the instrument used to measure ROM was not a goniometer. Despite the difference in ROM for some of the tasks favouring the Early group, the narrow margin for other tasks may explain why the OSS score was similar. Patients may not see a substantial increase in range of motion being the same as an indicator of a better outcome; as long as they reach a functional range that permits the return to some of their basic activities. Therefore, even though the Early group had greater improvements in ROM, both groups were functionally equivalent and consequently, one rehabilitation regime does not seem to be superior to the other on meeting patients' expectations. Moreover, at this stage, patients may consider that a better improvement in pain intensity and quality of sleep is more relevant than having a greater ROM of their shoulders $(33,34)$.

In our study, muscle recruitment was assessed with EMG. Overall, the integral of the 5 muscles showed some changes between groups but with high variability, which indicates that the amount of work done by each muscle was similar between groups and time points. However, as mentioned previously, the Conservative group generally showed a reduction in ROM over the tasks. Therefore, although groups may have equivalent muscle recruitment, Early rehabilitation may facilitate an earlier return to activities. The similar amount of work done and EMG amplitude, but with better ROM for the Early group, indicates that their shoulder muscles may be more efficient than the Conservative group, i.e. patients in the Early group needed 
equivalent muscle activity to perform greater joint excursions (35). This rationale is supported by other studies showing that the amount of power generated by muscles is not associated with an increase in EMG activity (36).

We found that the Early group had a higher number of re-tear events. However, three patients from the Conservative group did not attend their scan appointment compared to one from the Early group, thus, additional events in the Conservative group may have been missed. Moreover, the Early group had a greater number of smokers; smoking has been linked to worse outcomes and is considered a risk factor for rotator cuff tears (37). Although a higher number of re-tear events was found for the Early group only two patients were symptomatic. This finding corroborates with other studies reporting that even if a re-tear occurs patients may present significant improvement of their pain and strength (38-40).

\section{Limitations}

The sample size planned was not achieved and considerable lost to follow-up was observed, therefore, descriptive statistics was preferred as the study would have limited power to determine whether possible non-significant statistical differences between groups were not truly different (41). These limitations may limit the applicability of our findings, it is possible that due to missing values the treatment effects have been underestimated or overestimated $(42,43)$.

\section{CONCLUSION}

317 This study suggests that early rehabilitation is not superior to conservative 318 rehabilitation in improving function and quality of life. There is some indication that 
The authors have no conflict of interest to report.

\section{REFERENCES}

1. Yamamoto A, Takagishi K, Osawa T, Yanagawa T, Nakajima D, Shitara H, et al. Prevalence and risk factors of a rotator cuff tear in the general population. Journal of Shoulder and Elbow Surgery. 2010;19(1):116-20.

2. Thigpen CA, Shaffer MA, Gaunt BW, Leggin BG, Williams GR, Wilcox RB. The American Society of Shoulder and Elbow Therapists' consensus statement on rehabilitation following arthroscopic rotator cuff repair. Journal of Shoulder and Elbow Surgery. 2016;25(4):521-35. 3. Kuhn JE, Dunn WR, Sanders R, Baumgarten KM, Bishop JY, Brophy RH, et al. Effectiveness of physical therapy in treating atraumatic full-thickness rotator cuff tears: a multicenter prospective cohort study. Journal of Shoulder and Elbow Surgery. 2013;22(10):1371--9.

4. Keener JD, Galatz LM, Stobbs G, Patton R, Yamaguchi K, Stobbs-Cucchi G, et al. Rehabilitation Following Arthroscopic Rotator Cuff Repair A Prospective Randomized Trial of Immobilization Compared with Early Motion. Journal of Bone and Joint Surgery-American Volume. 2014;96(1):11--9. 5. Parsons BO, Gruson KI, Chen DD, Harrison AK, Gladstone J, Flatow EL. Does slower rehabilitation after arthroscopic rotator cuff repair lead to long-term stiffness? Journal of Shoulder and Elbow Surgery. 2010;19(7):1034-9.

6. Lin TW, Cardenas L, Soslowsky LJ. Biomechanics of tendon injury and repair. Journal of Biomechanics. 2004;37(6):865-77.

7. Keener JD. Revision Rotator Cuff Repair. Clinics in Sports Medicine. 2012;31(4):713 - 25.

8. Mazuquin BF, Wright AC, Russell S, Monga P, Selfe J, Richards J. Effectiveness of early compared with conservative rehabilitation for patients having rotator cuff repair surgery: an overview of systematic reviews. British Journal of Sports Medicine. 2018;52(2):111 - 21.

9. Duc C, Pichonnaz C, Bassin J-P, Farron A, Jolles BM, Aminian K. Evaluation of muscular activity duration in shoulders with rotator cuff tears using inertial sensors and electromyography. Physiological measurement. 2014;35(12):2389-400.

10. de Witte PB, Henseler JF, van Zwet EW, Nagels J, Nelissen RGHH, de Groot JH. Cranial humerus translation, deltoid activation, adductor co-activation and rotator cuff disease - Different patterns in rotator cuff tears, subacromial impingement and controls. Clinical Biomechanics. 2014;29(1):26-32.

11. Moher D, Hopewell S, Schulz KF, Montori V, Gotzsche PC, Devereaux PJ, et al. CONSORT 2010 Explanation and Elaboration: updated guidelines for reporting parallel group randomised trials. BMJ. 2010;340:c869. 
12. Booker S, Alfahad N, Scott M, Gooding B, Wallace WA. Use of scoring systems for assessing and reporting the outcome results from shoulder surgery and arthroplasty. World journal of orthopedics. 2015;6(2):244--51.

13. Beard DJ, Rees JL, Cook JA, Rombach I, Cooper C, Merritt N, et al. Arthroscopic subacromial decompression for subacromial shoulder pain (CSAW): A multicentre, pragmatic, parallel group, placebo-controlled, three-group, randomised surgical trial. The Lancet. 2018;391(10118):329--38. 14. Coretti S, Ruggeri M, McNamee P. The minimum clinically important difference for EQ-5D index: a critical review. Expert Review of Pharmacoeconomics \\& Outcomes Research. 2014;14(2):221--33.

15. EuroQoL. EQ-5D-5L Health Questionnaire English version for the UK. 2009:1--3.

16. Garofalo P. Development of motion analysis protocols based on inertial sensors: Univesity of Bologna; 2010.

17. Parel I, Cutti AG, Fiumana G, Porcellini G, Verni G, Accardo AP. Ambulatory measurement of the scapulohumeral rhythm: Intra- and inter-operator agreement of a protocol based on inertial and magnetic sensors. Gait \& Posture. 2012;35:636-40.

18. Kolk A, Henseler JF, de Witte PB, van Zwet EW, van der Zwaal P, Visser CPJ, et al. The effect of a rotator cuff tear and its size on three-dimensional shoulder motion. Clinical Biomechanics. 2017;45:43-51.

19. de Witte PB, van der Zwaal P, van Arkel ERa, Nelissen RGHH, de Groot JH. Pathologic deltoid activation in rotator cuff tear patients: normalization after cuff repair? Medical \& Biological Engineering \& Computing. 2014;52(3):241-9.

20. De Luca C. Electromyography. Encyclopedia of Medical Devices and Instrumentation. 2006. 21. Dancey CP, Reidy J. Statistics without maths for psychology : using SPSS for Windows: Prentice Hall; 2004. 612 p.

22. Mazzocca AD, Arciero RA, Shea KP, Apostolakos JM, Solovyova O, Gomlinski G, et al. The Effect of Early Range of Motion on Quality of Life, Clinical Outcome, and Repair Integrity After Arthroscopic Rotator Cuff Repair. Arthroscopy: The Journal of Arthroscopic \\& Related Surgery. 2017;33(6):1138-48.

23. van Kampen Da, Willems WJJ, van Beers LWAH, Castelein RM, Scholtes VaB, Terwee CB. Determination and comparison of the smallest detectable change (SDC) and the minimal important change (MIC) of four-shoulder patient-reported outcome measures (PROMs). Journal of Orthopaedic Surgery and Research. 2013;8:40.

24. Christiansen DH, Frost P, Falla D, Haahr JP, Frich LH, Svendsen SW. Responsiveness and Minimal Clinically Important Change: A Comparison Between 2 Shoulder Outcome Measures. The Journal of orthopaedic and sports physical therapy. 2015;45(8):620-5.

25. Carr AJ, Cooper CD, Campbell MK, Rees JL, Moser J, Beard DJ, et al. Clinical effectiveness and cost-effectiveness of open and arthroscopic rotator cuff repair the UK Rotator Cuff Surgery (UKUFF) randomised trial . Health technology assessment (Winchester, England). 2015;19(80):1-218.

26. Ryösä A, Laimi K, Äärimaa V, Lehtimäki K, Kukkonen J, Saltychev M. Surgery or conservative treatment for rotator cuff tear: a meta-analysis. Disability and Rehabilitation. 2017;39(14):1357-63. 27. Gurnani N, van Deurzen DFP, van den Bekerom MPJ. Shoulder-specific outcomes 1 year after nontraumatic full-thickness rotator cuff repair: a systematic literature review and meta-analysis. Shoulder \& Elbow. 2017;9(4):247-57.

28. Kim YSS, Chung SW, Kim JY, Ok JHH, Park I, Oh JH. Is Early Passive Motion Exercise Necessary After Arthroscopic Rotator Cuff Repair? American Journal of Sports Medicine. 2012;40(4):815-21.

29. Koh KH, Lim TK, Shon MS, Park YE, Lee SW, Yoo JC. Effect of immobilization without passive exercise after rotator cuff repair: randomized clinical trial comparing four and eight weeks of immobilization. The Journal of bone and joint surgeryAmerican volume. 2014;96(6):e44.

30. Vidt ME, Santago AC, Marsh AP, Hegedus EJ, Tuohy CJ, Poehling GG, et al. The effects of a rotator cuff tear on activities of daily living in older adults: A kinematic analysis. Journal of Biomechanics. 2016. 
31. Fritz JM, Inawat RR, Slavens BA, McGuire JR, Ziegler DW, Tarima SS, et al. Assessment of Kinematics and Electromyography Following Arthroscopic Single-Tendon Rotator Cuff Repair. PM and R. 2017;9(5):464-76.

32. Muir SW, Corea CL, Beaupre L. Evaluating change in clinical status: reliability and measures of agreement for the assessment of glenohumeral range of motion. North American journal of sports physical therapy 2010;5(3):98-110.

33. Minns Lowe CJ, Moser J, Barker K. Living with a symptomatic rotator cuff tear 'bad days, bad nights': a qualitative study. BMC Musculoskeletal Disorders. 2014;15(1):228.

34. Imam MA, Albers MBV, Shin J, Shaikh H, Naendrup J-H, Musahl V, et al. What Do Patients Expect of Rotator Cuff Repair and Does it Matter. Arthroscopy. 2017;33(10):e52.

35. Wakeling JM, Lee SSM, Arnold AS, de Boef Miara M, Biewener AA. A Muscle's Force Depends on the Recruitment Patterns of Its Fibers. Annals of Biomedical Engineering. 2012;40(8):1708-20. 36. Wakeling JM, Blake OM, Chan HK. Muscle coordination is key to the power output and mechanical efficiency of limb movements. The Journal of Experimental Biology. 2010;213(3):487. 37. Baumgarten KM, Gerlach D, Galatz LM, Teefey SA, Middleton WD, Ditsios K, et al. Cigarette smoking increases the risk for rotator cuff tears. Clinical Orthopaedics and Related Research. 2010;468(6):1534-41.

38. Sheps DM, Silveira A, Beaupre L, Styles-Tripp F, Balyk R, Lalani A, et al. Early Active Motion Versus Sling Immobilization After Arthroscopic Rotator Cuff Repair: A Randomized Controlled Trial. Arthroscopy: The Journal of Arthroscopic \\& Related Surgery. 2019;35(3):749--60.e2.

39. Minagawa H, Yamamoto N, Abe H, Fukuda M, Seki N, Kikuchi K, et al. Prevalence of symptomatic and asymptomatic rotator cuff tears in the general population: From mass-screening in one village. Journal of Orthopaedics. 2013;10(1):8-12.

40. Lädermann A, Denard PJ, Burkhart SS. Management of failed rotator cuff repair: a systematic review. Journal of ISAKOS: Joint Disorders \&amp;amp; Orthopaedic Sports Medicine. 2016;1(1):32.

41. Akobeng AK. Understanding type I and type II errors, statistical power and sample size. Acta Paediatrica. 2016;105(6):605--9.

42. Higgins JPT, Green S. Cochrane Handbook for Systematic Reviews of Interventions: The Cochrane Collaboration; 2011.

43. Fielding $S$, Fayers $P$, Ramsay CR. Analysing randomised controlled trials with missing data: Choice of approach affects conclusions. Contemporary Clinical Trials. 2012;33(3):461-9. 
m

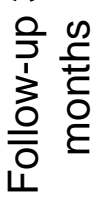

454

0

455 은

456

457

458

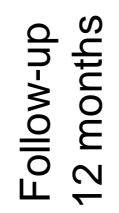

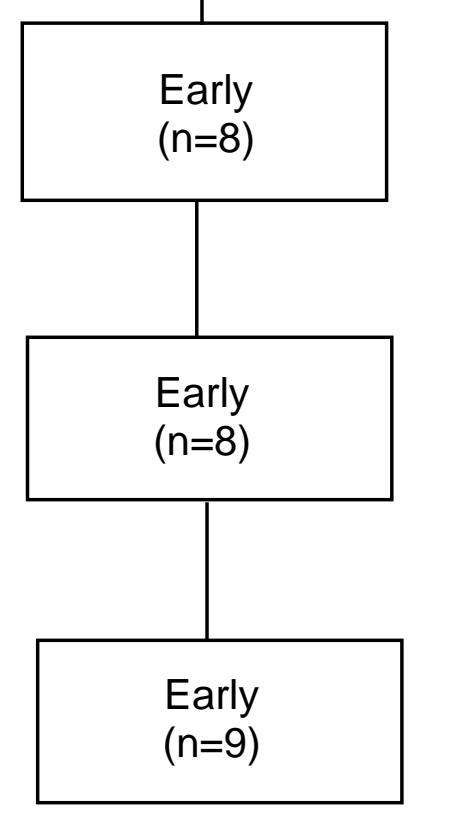

Excluded $(\mathrm{n}=79)$ :

$$
(n=99)
$$

- Refused to participate $(n=57)$

- Exclusion criteria $(n=22)$

459 Figure 1. Flow diagram of patient recruitment, allocation and analyses. 
TABLE 1. Range of motion tasks.

\begin{tabular}{|c|c|c|}
\hline Task & Description & Movement involved \\
\hline 1) Combing & $\begin{array}{l}\text { Simulated combing } \\
\text { movement taking the hand } \\
\text { to the back of the head. }\end{array}$ & $\begin{array}{l}\text { Shoulder abduction (coronal plane) } \\
\text { combined with external rotation } \\
\text { (transverse plane). }\end{array}$ \\
\hline 2) Abduction & $\begin{array}{l}\text { Maximal abduction in the } \\
\text { coronal plane. }\end{array}$ & Abduction only (coronal plane). \\
\hline 3) Carrying & $\begin{array}{l}\text { With the arms resting } \\
\text { besides the body, the } \\
\text { participant took a dumbbell } \\
\text { to the furthest point in a } \\
\text { horizontal shoulder } \\
\text { abduction and adduction } \\
\text { movement with the elbow in } \\
\text { complete extension. }\end{array}$ & $\begin{array}{l}\text { Horizontal shoulder adduction and } \\
\text { abduction (transverse plane). }\end{array}$ \\
\hline 4) Reaching & $\begin{array}{l}\text { The participants tried to } \\
\text { reach their opposite back } \\
\text { pocket. }\end{array}$ & $\begin{array}{l}\text { Shoulder extension (sagittal plane) } \\
\text { combined with internal rotation } \\
\text { (transverse plane) }\end{array}$ \\
\hline 5) Flexion & $\begin{array}{l}\text { Maximal forward flexion and } \\
\text { extension in the sagittal } \\
\text { plane. }\end{array}$ & Flexion only (sagittal plane) \\
\hline 6) Lifting & $\begin{array}{l}\text { With the arm resting beside } \\
\text { the body, the participant } \\
\text { raised a dumbbell }(1 \mathrm{~kg}) \text { to } \\
\text { the highest point above the } \\
\text { head. }\end{array}$ & Flexion only (sagittal plane) \\
\hline
\end{tabular}


TABLE 2. Baseline characteristics.

\begin{tabular}{|c|c|c|}
\hline & \multicolumn{2}{|c|}{ Group } \\
\hline & $\begin{array}{l}\text { Early } \\
\bar{x}(\mathrm{SD})\end{array}$ & $\begin{array}{c}\text { Conservative } \\
\bar{x} \text { (SD) }\end{array}$ \\
\hline \multicolumn{3}{|l|}{ Demographics } \\
\hline Age (years) & $55.2(8.1)$ & $58.3(11.7)$ \\
\hline Weight (kg) & $85.2(13.7)$ & $95.0(14.2)$ \\
\hline Height (m) & $1.71(0.08)$ & $1.75(0.08)$ \\
\hline \multicolumn{3}{|l|}{ Sex } \\
\hline Female (\%) & $3(30)$ & $3(30)$ \\
\hline Male (\%) & $7(70)$ & $7(70)$ \\
\hline \multicolumn{3}{|l|}{ Smoker } \\
\hline Yes (\%) & $3(30)$ & 0 \\
\hline No (\%) & $7(70)$ & $10(100)$ \\
\hline \multicolumn{3}{|l|}{ Diabetes } \\
\hline Yes (\%) & 0 & 0 \\
\hline No (\%) & $10(100)$ & $10(100)$ \\
\hline \multicolumn{3}{|l|}{ Side of surgery } \\
\hline Right (\%) & $5(50)$ & $7(30)$ \\
\hline Left (\%) & $5(50)$ & $3(30)$ \\
\hline \multicolumn{3}{|l|}{ Dominance } \\
\hline Right (\%) & $6(60)$ & $8(80)$ \\
\hline Left (\%) & $4(40)$ & $2(20)$ \\
\hline $\begin{array}{l}\text { Time from first symptoms to } \\
\text { surgery (months) }\end{array}$ & $20.0(13.0)$ & $9.80(4.2)$ \\
\hline
\end{tabular}

SD: standard deviation 
TABLE 3. Surgery characteristics.

\begin{tabular}{|c|c|c|c|}
\hline & $\begin{array}{l}\text { Early } \\
\text { (n) }\end{array}$ & $\begin{array}{c}\text { Conservative } \\
\text { (n) }\end{array}$ & $\begin{array}{c}\text { Total } \\
\text { (n) }\end{array}$ \\
\hline \multicolumn{4}{|l|}{ Muscle Affected } \\
\hline Supraspinatus & 4 & 3 & 7 \\
\hline Supra+Infra & 4 & 6 & 10 \\
\hline Multiple & 2 & 1 & 3 \\
\hline Total & 10 & 10 & 20 \\
\hline \multicolumn{4}{|l|}{ Tear Size } \\
\hline Small $(<1 \mathrm{~cm})$ & 2 & 2 & 4 \\
\hline Medium $(1-3 \mathrm{~cm})$ & 5 & 6 & 11 \\
\hline Large $(3-5 \mathrm{~cm})$ & 3 & 2 & 5 \\
\hline Total & 10 & 10 & 20 \\
\hline \multicolumn{4}{|l|}{ Thickness } \\
\hline Partial & 0 & 1 & 1 \\
\hline Total & 10 & 10 & 20 \\
\hline \multicolumn{4}{|l|}{ Fixation method } \\
\hline Single-row & 7 & 7 & 14 \\
\hline Double-row & 3 & 3 & 6 \\
\hline Total & 10 & 10 & 20 \\
\hline $\begin{array}{l}\text { Additional proce } \\
S A D\end{array}$ & 4 & 4 & 8 \\
\hline Multiple & 6 & 6 & 12 \\
\hline Total & 10 & 10 & 20 \\
\hline \multicolumn{4}{|c|}{ Previous contralateral repair } \\
\hline Yes & 3 & 1 & 4 \\
\hline No & 7 & 9 & 16 \\
\hline Total & 10 & 10 & 20 \\
\hline
\end{tabular}

SAD: subacromial decompression. 
TABLE 4. Self-reported sling usage.

\section{Group}

\begin{tabular}{ccccc} 
Number of weeks w/ sling & $\begin{array}{c}\text { Early } \\
(\mathbf{n})\end{array}$ & $\begin{array}{c}\text { Conservative } \\
(\mathbf{n})\end{array}$ & Total \\
\hline$<1$ & 4 & 0 & 4 \\
2 & 1 & 0 & 1 \\
3 & 2 & 1 & 3 \\
4 & 1 & 0 & 1 \\
5 & 1 & 0 & 1 \\
6 & 1 & 6 & 7 \\
Total & $>6$ & 0 & 1 & 1 \\
\hline
\end{tabular}


TABLE 5. Questionnaires and ROM results.

\begin{tabular}{|c|c|c|c|c|}
\hline \multirow[b]{2}{*}{ Clinical score } & \multicolumn{2}{|r|}{ Early } & \multicolumn{2}{|c|}{ Conservative } \\
\hline & Median & IQR (25-75\%) & Median & IQR (25-75\%) \\
\hline \multicolumn{5}{|l|}{ OSS } \\
\hline Baseline & 27.5 & $15-35.2$ & 34.5 & $27.7-40.5$ \\
\hline 3 months & 34.5 & $27.5-43.5$ & 43 & $40-44$ \\
\hline 6 months & 46 & $42.5-48$ & 42 & $34.5-47$ \\
\hline \multicolumn{5}{|l|}{ EQ-5D } \\
\hline Baseline & 10 & $7.7-12.5$ & 7.5 & $6-9.7$ \\
\hline 3 months & 8.5 & 6-13.7 & 6 & $5-14$ \\
\hline 6 months & 6 & $5.5-11$ & 6 & 5-12 \\
\hline \multicolumn{5}{|l|}{ ROM $\left(^{\circ}\right)$} \\
\hline \multicolumn{5}{|l|}{ Combing } \\
\hline Baseline & 79.2 & $65.5-113.2$ & 87.6 & $72.9-96.4$ \\
\hline 3 months & 93.3 & $89.4-101.7$ & 96.4 & $85.8-107.6$ \\
\hline 6 months & 102.0 & $96.6-118.7$ & 95.3 & $66.2-103.8$ \\
\hline \multicolumn{5}{|l|}{ Abduction } \\
\hline Baseline & 63.2 & $29.4-86.4$ & 91.9 & $50.2-113.3$ \\
\hline 3 months & 92.5 & $81.4-103.5$ & 100.1 & $77.7-110.5$ \\
\hline 6 months & 115.8 & $94.9-117.3$ & 101.8 & $64.2-115.5$ \\
\hline \multicolumn{5}{|l|}{ Carrying } \\
\hline Baseline & 43.5 & $19.8-64.6$ & 64.7 & $43.2-71.6$ \\
\hline 3 months & 56.8 & $41.4-85.7$ & 57.0 & $42.9-68.3$ \\
\hline 6 months & 78.6 & $71.0-87.9$ & 80.5 & $43.3-90.2$ \\
\hline \multicolumn{5}{|l|}{ Reaching } \\
\hline Baseline & 13.6 & $3.14-20.8$ & 15.4 & $11.9-20.6$ \\
\hline 3 months & 20.3 & $10.0-25.8$ & 15.4 & 9.9-21.1 \\
\hline 6 months & 19.5 & $-2.2-29.5$ & 21.5 & $4.6-22.9$ \\
\hline \multicolumn{5}{|l|}{ Flexion } \\
\hline Baseline & 105.9 & $66.7-138.9$ & 131.0 & $103.4-152.5$ \\
\hline 3 months & 130.0 & $125.2-144.9$ & 125.1 & 104.1-1401. \\
\hline 6 months & 152.1 & $147.7-165.9$ & 140.0 & 104.3-157.9 \\
\hline \multicolumn{5}{|l|}{ Lifting } \\
\hline Baseline & 83.9 & $60.3-107.7$ & 129.4 & $87.4-150.4$ \\
\hline 3 months & 124.6 & $97.8-141.2$ & 119.9 & $82.9-142.4$ \\
\hline 6 months & 152.8 & $141.4-154.1$ & 139.0 & $83.9-157.1$ \\
\hline
\end{tabular}

IQR: interquartile range, OSS: Oxford Shoulder Score. 
SUPPLEMENTARY FILE A. Early and Conservative protocols.

\section{Early Rehabilitation}

$\begin{array}{ll}\text { Stage 1 } & \text { - Sling for comfort only } \\ \text { On } & \text { - Advice on sling management } \\ \text { Discharge - } & \text { - Neck, elbow, wrist \& hand exercises } \\ 4 \text { weeks } & \text { - Postural awareness and scapula control } \\ & \text { - Active assisted closed chain ROM in safe } \\ & \text { - zone } \\ & \text { - Kinetic chain rehabilitation } \\ & \text { - Thoracic spine ROM' } \\ & \text { rotation and HBB }\end{array}$

Stage 2

4-6 weeks

- Progress from active-assisted to active ROM beyond safe zone (short to long lever).

- HBB within limits of pain

- Begin cuff control exercises and submaximal (approx. 30\%) isometric strengthening in neutral through available range

\section{Stage 3}

6-8 weeks

- Commence open chain rotator cuff strengthening (short to long lever)

- Active short lever kinetic chain rehabilitation of the affected arm progressing to long lever function movement

- Begin stretching into combined movement ranges

\section{Conservative Rehabilitation}

Stage 1

On

Discharge -

4 weeks

\section{Stage 2}

4-6 weeks

\section{Stage 3}

6-8 weeks

- Sling 6 weeks, if abduction wedge then reduce to standard sling at 2-3 weeks

- Advice on sling management

- Neck, elbow, wrist \& hand exercises

- Postural awareness and scapula control

- Active assisted closed chain ROM in safe zone

- Kinetic chain rehabilitation

- Thoracic spine ROM

- Avoid combined abduction and external rotation and $\mathrm{HBB}$

- Continue with stage 1

- Light proprioceptive exercises

- Remain in sling

Continue 
SUPPLEMENTARY FILE A (CONTINUE). Early and Conservative protocols.

\section{Early Rehabilitation}

\begin{tabular}{|c|c|c|c|}
\hline $\begin{array}{l}\text { Stage } 4 \\
8-12 \text { weeks }\end{array}$ & $\begin{array}{l}\text { - Progression of full kinetic chain } \\
\text { rehabilitation } \\
\text { - Progression of stretching } \\
\text { - Patient-specific functional/sports training } \\
\text { - Begin combined abduction and external } \\
\text { rotation }\end{array}$ & $\begin{array}{l}\text { Stage } 4 \\
8-12 \text { weeks }\end{array}$ & $\begin{array}{l}\text { - Commence open chain rotator cuff } \\
\text { strengthening (short to long lever) } \\
\text { - Active short lever kinetic chain rehabilitation } \\
\text { of the affected arm progressing to long } \\
\text { lever function movement } \\
\text { - Begin stretching into combined movement } \\
\text { ranges }\end{array}$ \\
\hline $\begin{array}{l}\text { Stage } 5 \\
12 \text { weeks }+\end{array}$ & $\begin{array}{l}\text { - Continue and progress with stage } 4 \\
\text { - Manual therapy to address ROM deficits }\end{array}$ & $\begin{array}{l}\text { Stage } 5 \\
12 \text { weeks + }\end{array}$ & $\begin{array}{l}\text { - Begin combined abduction and external } \\
\text { rotation } \\
\text { - Full kinetic chain rehabilitation } \\
\text { - Patient-specific functional/sports training } \\
\text { - Manual therapy to address ROM deficits }\end{array}$ \\
\hline & Milestones & & Milestones \\
\hline Week 4 & $\begin{array}{l}\text { ROM } 75 \%-80 \% \text { of normal, sling } \\
\text { discarded, return to driving as able, } \\
\text { return to sedentary work }\end{array}$ & Week 8 & $\begin{array}{l}\text { ROM } 75 \%-80 \% \text { of normal, sling discarded, } \\
\text { return to driving as able, return to sedentary } \\
\text { work }\end{array}$ \\
\hline 3-6 months & $\begin{array}{l}\text { - Full active ROM, can consider return to } \\
\text { non-contact sport. } \\
\text { - Return to manual work as guided by } \\
\text { surgeon/physiotherapist }\end{array}$ & 3-6 months & $\begin{array}{l}\text { - Full active ROM, can consider return to } \\
\text { non-contact sport. } \\
\text { - Return to manual work as guided by } \\
\text { surgeon/physiotherapist }\end{array}$ \\
\hline 6 months & Unrestricted activity & 6 months & - Unrestricted activity \\
\hline
\end{tabular}

HBB: hand behind back.

\section{Conservative Rehabilitation}

Commence open chain rotator cuff of the affected arm progressing to long ranges

rotation

- Patient-specific functional/sports training

\section{Milestones} ro driving as able, return to sedentary

Full active ROM, can consider return to

surgeon/physiotherapist

- Unrestricted activity 
SUPPLEMENTARY FILE B. Muscle activity for the various tasks at baseline, three and six months follow-ups.

\begin{tabular}{|c|c|c|c|c|c|c|c|c|c|c|}
\hline \multirow[b]{2}{*}{ EMG (\%) } & \multicolumn{5}{|c|}{$\begin{array}{c}\text { Early } \\
\text { Median (IQR 25-75\%) }\end{array}$} & \multicolumn{5}{|c|}{$\begin{array}{c}\text { Conservative } \\
\text { Median (IQR 25-75\%) }\end{array}$} \\
\hline & UT & $A D$ & MD & PD & BC & UT & AD & MD & PD & BC \\
\hline \multicolumn{11}{|l|}{ Combing } \\
\hline Baseline & $\begin{array}{c}38.1 \\
(17.6- \\
51.6)\end{array}$ & $\begin{array}{c}32.6 \\
(21.1- \\
47.1)\end{array}$ & $\begin{array}{c}38.8 \\
(20.6- \\
54.5)\end{array}$ & $\begin{array}{c}30.8 \\
(17.1- \\
40.3)\end{array}$ & $\begin{array}{c}37.5 \\
(27.3- \\
51.5)\end{array}$ & $\begin{array}{c}31.3 \\
(22.3- \\
40.5)\end{array}$ & $\begin{array}{c}22.3 \\
(10.3- \\
39.2)\end{array}$ & $\begin{array}{c}25.5 \\
(16.8- \\
42.6)\end{array}$ & $\begin{array}{c}17.8 \\
(10.4- \\
26.1)\end{array}$ & $\begin{array}{c}35.8 \\
(20.7- \\
48.2)\end{array}$ \\
\hline 3 months & $\begin{array}{c}39.0 \\
(28.12- \\
50.9)\end{array}$ & $\begin{array}{c}43.6 \\
(35.7- \\
54.1)\end{array}$ & $\begin{array}{c}31.0 \\
(25.0- \\
37.5)\end{array}$ & $\begin{array}{c}13.1(9.1- \\
28.7)\end{array}$ & $\begin{array}{c}35.7 \\
(25.0- \\
50.0)\end{array}$ & $\begin{array}{c}31.4 \\
(21.8- \\
45.6)\end{array}$ & $\begin{array}{c}36.8 \\
(23.8- \\
45.7)\end{array}$ & $\begin{array}{c}35.9 \\
(32.0- \\
41.5)\end{array}$ & $\begin{array}{c}23.5 \\
(21.4- \\
32.5)\end{array}$ & $\begin{array}{c}36.6 \\
(27.3- \\
65.6)\end{array}$ \\
\hline 6 months & $\begin{array}{c}33.6 \\
(20.0- \\
45.6)\end{array}$ & $\begin{array}{c}41.1 \\
(33.7- \\
54.8)\end{array}$ & $\begin{array}{c}33.5 \\
(28.4- \\
41.7)\end{array}$ & $\begin{array}{c}23.4 \\
(14.4- \\
34.7)\end{array}$ & $\begin{array}{c}30.0 \\
(17.5- \\
49.6)\end{array}$ & $\begin{array}{c}33.0 \\
(23.6- \\
41.6)\end{array}$ & $\begin{array}{c}43.9 \\
(35.0- \\
52.5)\end{array}$ & $\begin{array}{c}30.5 \\
(18.0- \\
38.1)\end{array}$ & $\begin{array}{c}22.8 \\
(16.2- \\
32.3)\end{array}$ & $\begin{array}{c}48.4 \\
(35.6- \\
59.4)\end{array}$ \\
\hline \multicolumn{11}{|l|}{ Abduction } \\
\hline Baseline & $\begin{array}{c}45.7 \\
(24.0- \\
61.7)\end{array}$ & $\begin{array}{c}30.1 \\
(16.2- \\
47.0)\end{array}$ & $\begin{array}{c}49.8 \\
(32.5- \\
75.7)\end{array}$ & $\begin{array}{c}54.5 \\
(41.2- \\
66.0)\end{array}$ & $\begin{array}{c}20.0 \\
(15.3- \\
27.5)\end{array}$ & $\begin{array}{c}52.0 \\
(39.0- \\
72.3)\end{array}$ & $\begin{array}{c}46.5 \\
(39.1- \\
63.8)\end{array}$ & $\begin{array}{c}65.6 \\
(56.0- \\
77.9)\end{array}$ & $\begin{array}{c}49.6 \\
(31.5- \\
73.5)\end{array}$ & $\begin{array}{c}30.6 \\
(15.7- \\
55.6)\end{array}$ \\
\hline 3 months & $\begin{array}{l}50.0 \\
(39.6- \\
73.9)\end{array}$ & $\begin{array}{c}48.8 \\
(32.5-64)\end{array}$ & $\begin{array}{c}51.0 \\
(44.0- \\
68.1)\end{array}$ & $\begin{array}{c}52.9 \\
(31.2- \\
64.1)\end{array}$ & $\begin{array}{c}16.7(8.4- \\
35.7)\end{array}$ & $\begin{array}{c}61.8 \\
(45.0- \\
77.3)\end{array}$ & $\begin{array}{c}58.6 \\
(37.3- \\
71.5)\end{array}$ & $\begin{array}{c}69.2 \\
(49.2- \\
79.2)\end{array}$ & $\begin{array}{c}53.6 \\
(34.3- \\
71.7)\end{array}$ & $\begin{array}{c}28.2 \\
(23.5- \\
35.7)\end{array}$ \\
\hline 6 months & $\begin{array}{c}51.8 \\
(42.4- \\
56.0)\end{array}$ & $\begin{array}{c}63.4 \\
(47.0- \\
69.6)\end{array}$ & $\begin{array}{c}64.1 \\
(52.2- \\
68.6)\end{array}$ & $\begin{array}{c}53.5 \\
(44.2- \\
69.0)\end{array}$ & $\begin{array}{c}43.5 \\
(20.1- \\
51.0)\end{array}$ & $\begin{array}{c}58.9 \\
(44.7- \\
64.5)\end{array}$ & $\begin{array}{c}48.4 \\
(42.2- \\
64.0)\end{array}$ & $\begin{array}{c}54.5 \\
(37.9- \\
68.3)\end{array}$ & $\begin{array}{c}57.2 \\
(45.3- \\
67.0)\end{array}$ & $\begin{array}{r}17.7 \\
(15.0- \\
40.9)\end{array}$ \\
\hline
\end{tabular}


SUPPLEMENTARY FILE B (CONTINUED). Muscle activity for the various tasks at baseline, three and six months follow-ups.

\begin{tabular}{|c|c|c|c|c|c|c|c|c|c|c|}
\hline \multirow[b]{2}{*}{ EMG (\%) } & \multicolumn{5}{|c|}{$\begin{array}{c}\text { Early } \\
\text { Median (IQR 25-75\%) }\end{array}$} & \multicolumn{5}{|c|}{$\begin{array}{c}\text { Conservative } \\
\text { Median (IQR 25-75\%) }\end{array}$} \\
\hline & UT & AD & MD & PD & BC & UT & AD & MD & PD & $B C$ \\
\hline \multicolumn{11}{|l|}{ Carrying } \\
\hline Baseline & $\begin{array}{l}68.6 \\
(36.5- \\
78.9)\end{array}$ & $\begin{array}{l}73.7 \\
(42.4- \\
85.6)\end{array}$ & $\begin{array}{l}40.0 \\
(21.4- \\
74.5)\end{array}$ & $\begin{array}{l}30.0 \\
(20.1- \\
65.0)\end{array}$ & $\begin{array}{l}60.0 \\
(38.6- \\
78.8)\end{array}$ & $\begin{array}{l}71.4 \\
(59.3- \\
78.2)\end{array}$ & $\begin{array}{l}74.1 \\
(55.5- \\
87.7)\end{array}$ & $\begin{array}{l}52.0 \\
(40.6- \\
77.6)\end{array}$ & $\begin{array}{l}52.5 \\
(48.0- \\
69.7)\end{array}$ & $\begin{array}{l}80.0 \\
(50.5- \\
92.8)\end{array}$ \\
\hline 3 months & $\begin{array}{c}66.2 \\
(47.2- \\
81.1)\end{array}$ & $\begin{array}{c}61.4 \\
(48.4- \\
84.0)\end{array}$ & $\begin{array}{c}78.0 \\
(22.9- \\
88.4)\end{array}$ & $\begin{array}{c}60.0 \\
(28.2- \\
81.5)\end{array}$ & $\begin{array}{c}73.3 \\
(71.4- \\
77.1)\end{array}$ & $\begin{array}{c}73.1 \\
(55.3- \\
80.9)\end{array}$ & $\begin{array}{c}79.5 \\
(61.1- \\
90.6)\end{array}$ & $\begin{array}{c}80.1 \\
(58.9- \\
90.0)\end{array}$ & $\begin{array}{c}77.1 \\
(55.8- \\
83.6)\end{array}$ & $\begin{array}{c}76.9 \\
(64.9- \\
83.4)\end{array}$ \\
\hline 6 months & $\begin{array}{c}67.7 \\
(44.9- \\
86.3)\end{array}$ & $\begin{array}{c}80.1 \\
(63.0- \\
84.8)\end{array}$ & $\begin{array}{r}66.9 \\
(50.6- \\
78.7)\end{array}$ & $\begin{array}{c}65.8 \\
(55.1- \\
71.0)\end{array}$ & $\begin{array}{c}69.8 \\
(62.8- \\
73.7)\end{array}$ & $\begin{array}{c}80.7 \\
(63.2- \\
86.9)\end{array}$ & $\begin{array}{c}83.6 \\
(57.9- \\
91.3)\end{array}$ & $\begin{array}{c}85.7 \\
(57.3- \\
90.2)\end{array}$ & $\begin{array}{c}77.1 \\
(69.0- \\
86.6)\end{array}$ & $\begin{array}{c}76.1 \\
(51.8- \\
88.4)\end{array}$ \\
\hline \multicolumn{11}{|l|}{ Reaching } \\
\hline Baseline & $\begin{array}{l}11.2(5.3- \\
19.0)\end{array}$ & $\begin{array}{l}4.9(1.6- \\
11.0)\end{array}$ & $\begin{array}{l}10.2(6.7- \\
16.8)\end{array}$ & $\begin{array}{c}31.5 \\
(17.7- \\
42.5)\end{array}$ & $\begin{array}{l}5.9(0- \\
12.2)\end{array}$ & $\begin{array}{l}3.6(2.6- \\
15.2)\end{array}$ & $\begin{array}{l}2.6(1.2- \\
9.4)\end{array}$ & $\begin{array}{l}6.8(2.5- \\
15.3)\end{array}$ & $\begin{array}{c}27.7 \\
(10.9- \\
50.5)\end{array}$ & $\begin{array}{l}4.2(1.5- \\
14.3)\end{array}$ \\
\hline 3 months & $\begin{array}{l}8.3(4.5- \\
21.5)\end{array}$ & $\begin{array}{l}14.5(5.4- \\
18.0)\end{array}$ & $\begin{array}{l}8.9(3.1- \\
13.6)\end{array}$ & $\begin{array}{l}34.8(20- \\
48)\end{array}$ & $\begin{array}{c}16.7 \\
(14.2- \\
33.3)\end{array}$ & $\begin{array}{l}12.5(1.8- \\
17.8)\end{array}$ & $\begin{array}{l}5.3(2.2- \\
\quad 6.7)\end{array}$ & $\begin{array}{l}7.7(3.9- \\
18.0)\end{array}$ & $\begin{array}{c}23.1 \\
(13.7-60)\end{array}$ & $\begin{array}{l}15.4(7.3- \\
30.0)\end{array}$ \\
\hline 6 months & $\begin{array}{l}7.0(3.0- \\
13.5)\end{array}$ & $\begin{array}{l}3.5(1.9- \\
5.3)\end{array}$ & $\begin{array}{l}5.7(3.2- \\
\quad 8.9)\end{array}$ & $\begin{array}{c}27.8 \\
(23.7- \\
52.7) \\
\end{array}$ & $\begin{array}{l}18.4(6.2- \\
48.9)\end{array}$ & $\begin{array}{l}4.6(2.9- \\
5.4)\end{array}$ & $\begin{array}{c}3.7 \text { (2.6- } \\
5.8)\end{array}$ & $\begin{array}{c}7.1(3.7- \\
13.9)\end{array}$ & $\begin{array}{c}37.1 \\
(17.0- \\
55.6)\end{array}$ & $\begin{array}{c}15.5(8.0- \\
23.9)\end{array}$ \\
\hline
\end{tabular}

Continue 
SUPPLEMENTARY FILE B (CONTINUED). Muscle activity for the various tasks at baseline, three and six months follow-ups.

\begin{tabular}{|c|c|c|c|c|c|c|c|c|c|c|}
\hline \multirow[b]{2}{*}{ EMG (\%) } & \multicolumn{5}{|c|}{$\begin{array}{c}\text { Early } \\
\text { Median (IQR 25-75\%) }\end{array}$} & \multicolumn{5}{|c|}{$\begin{array}{c}\text { Conservative } \\
\text { Median (IQR 25-75\%) }\end{array}$} \\
\hline & UT & AD & MD & PD & BC & UT & AD & MD & PD & BC \\
\hline \multicolumn{11}{|l|}{ Flexion } \\
\hline Baseline & $\begin{array}{c}40.4 \\
(32.7- \\
45.8)\end{array}$ & $\begin{array}{c}45.7 \\
(30.7- \\
54.9)\end{array}$ & $\begin{array}{c}44.6 \\
(23.8- \\
52.9)\end{array}$ & $\begin{array}{c}45.3 \\
(29.4- \\
53.6)\end{array}$ & $\begin{array}{c}32.2 \\
(25.7-52)\end{array}$ & $\begin{array}{c}48.4 \\
(37.3- \\
52.6)\end{array}$ & $\begin{array}{c}46.7 \\
(36.3- \\
60.2)\end{array}$ & $\begin{array}{c}50.8 \\
(40.86- \\
67.5)\end{array}$ & $\begin{array}{c}43.6 \\
(30.7- \\
54.9)\end{array}$ & $\begin{array}{c}38.2 \\
(30.1- \\
48.3)\end{array}$ \\
\hline 3 months & $\begin{array}{c}44.4 \\
(40.4-60)\end{array}$ & $\begin{array}{c}49.0 \\
(47.2- \\
61.2)\end{array}$ & $\begin{array}{c}42.5 \\
(33.3- \\
50.8)\end{array}$ & $\begin{array}{c}51.3 \\
(39.4- \\
72.7)\end{array}$ & $\begin{array}{c}33.3 \\
(36.6- \\
45.7)\end{array}$ & $\begin{array}{c}51.9 \\
(33.5- \\
64.2)\end{array}$ & $\begin{array}{c}46.7 \\
(38.5- \\
66.4)\end{array}$ & $\begin{array}{c}56.4 \\
(39.0- \\
64.6)\end{array}$ & $\begin{array}{c}49.5 \\
(40.6- \\
52.4)\end{array}$ & $\begin{array}{c}40.0 \\
(30.7- \\
56.0)\end{array}$ \\
\hline 6 months & $\begin{array}{c}49.5 \\
(37.6- \\
78.2)\end{array}$ & $\begin{array}{c}65.7 \\
(55.1- \\
67.4)\end{array}$ & $\begin{array}{c}56.5 \\
(48.1- \\
74.8)\end{array}$ & $\begin{array}{c}51.1 \\
(38.2- \\
78.2)\end{array}$ & $\begin{array}{c}55.6 \\
(26.3- \\
76.8)\end{array}$ & $\begin{array}{c}57.1 \\
(49.0- \\
63.4)\end{array}$ & $\begin{array}{c}45.6 \\
(37.6- \\
73.2)\end{array}$ & $\begin{array}{c}59.7 \\
(43.6- \\
73.6)\end{array}$ & $\begin{array}{c}64.5 \\
(56.7- \\
74.0)\end{array}$ & $\begin{array}{c}48.9 \\
(35.2- \\
59.2)\end{array}$ \\
\hline \multicolumn{11}{|l|}{ Lifting } \\
\hline Baseline & $\begin{array}{c}36.1 \\
(31.6- \\
47.1)\end{array}$ & $\begin{array}{c}48.6 \\
(37.3- \\
66.6)\end{array}$ & $\begin{array}{c}41.3 \\
(25.3- \\
51.7)\end{array}$ & $\begin{array}{l}43.3 \\
(27.3- \\
72.0)\end{array}$ & $\begin{array}{l}57.5 \\
(35.2- \\
72.5)\end{array}$ & $\begin{array}{c}49.5 \\
(42.2- \\
69.1)\end{array}$ & $\begin{array}{l}55.7 \\
(48.4- \\
72.7)\end{array}$ & $\begin{array}{c}56.6 \\
(39.8- \\
76.2)\end{array}$ & $\begin{array}{c}70.0 \\
(39.7- \\
86.6)\end{array}$ & $\begin{array}{c}55.0 \\
(47.9- \\
86.6)\end{array}$ \\
\hline 3 months & $\begin{array}{c}52.4 \\
(38.9- \\
70.8)\end{array}$ & $\begin{array}{c}64.2 \\
(42.1- \\
81.2)\end{array}$ & $\begin{array}{l}47.5 \\
(29.7- \\
72.1)\end{array}$ & $\begin{array}{l}74.0 \\
(25.0- \\
90.1)\end{array}$ & $\begin{array}{c}53.3 \\
(39.2- \\
67.6)\end{array}$ & $\begin{array}{c}59.4 \\
(54.8- \\
67.2)\end{array}$ & $\begin{array}{c}67.3 \\
(49.4- \\
81.3)\end{array}$ & $\begin{array}{c}63.5 \\
(58.3- \\
84.4)\end{array}$ & $\begin{array}{c}61.9 \\
(57.5- \\
67.4)\end{array}$ & $\begin{array}{c}60.0 \\
(55.9- \\
88.1)\end{array}$ \\
\hline 6 months & $\begin{array}{c}61.9 \\
(53.6- \\
72.3) \\
\end{array}$ & $\begin{array}{c}77.2 \\
(67.0- \\
89.9) \\
\end{array}$ & $\begin{array}{c}67.4 \\
(58.9- \\
75.5) \\
\end{array}$ & $\begin{array}{c}62.3 \\
(54.2- \\
85.8) \\
\end{array}$ & $\begin{array}{c}80.4 \\
(69.7- \\
90.1) \\
\end{array}$ & $\begin{array}{c}55.0 \\
(50.1- \\
72.8) \\
\end{array}$ & $\begin{array}{c}48.8 \\
(44.1- \\
66.3) \\
\end{array}$ & $\begin{array}{c}53.2 \\
(47.2- \\
78.4) \\
\end{array}$ & $\begin{array}{c}72.2 \\
(60.3- \\
81.2) \\
\end{array}$ & $\begin{array}{c}60.0 \\
(54.8- \\
72.9) \\
\end{array}$ \\
\hline
\end{tabular}

AD: anterior deltoid, MD: middle deltoid, PD: posterior deltoid, BC: biceps brachii, IQR: interquartile range. 